\title{
Gender, Patient Comfort and the Neurosurgical Operating Room
}

\author{
Rebecca Zener, Mark Bernstein
}

\begin{abstract}
Background: Neurosurgical patients may be unaware of components of their intra-operative care. The relationship between patient gender and comfort level in the neurosurgical operating room (OR) has not been previously studied. Our objective was to gain insight into patients' perspective of the OR environment, including staffing and observers, the role of medical students, catheterization, exposure, and verbiage, using a qualitative needs assessment. Methods: Face-to-face semi-structured interviews were conducted with 20 patients (14 female, six male) who had a neurosurgical operation under general anesthetic within the previous two years. The majority underwent craniotomy for benign tumours. Interviews were transcribed and subjected to modified thematic analysis. Results: Nine themes emerged: 1) perception of the intra-operative environment varies between men and women; 2) lacking awareness about observers is anxiety-provoking for women; 3) being unaware of the hands-on involvement of students is a concern for all patients; 4) disclosure of implantation of foreign and permanent materials into patients is important; 5) catheterization is anxiety provoking for women; 6) pre-operative menstruation screening may minimize embarrassment for women; 7) patients perceive extraneous conversation as a distraction for surgeons; 8) patients trust their surgeon; 9) a relationship exists between interviewer gender and patient comfort in the interview. Conclusion: Although most male and female patients are unaware of OR activities, they are generally not fearful since they trust their surgeon. Women appear to have greater information needs. Patients' information needs must be met without provoking anxiety and yet preserving their personal sense of modesty in the intra-operative environment.
\end{abstract}

RÉSUMÉ: Le sexe et le confort du patient en salle d'opération neurochirurgicale. Contexte : Les patients traités en neurochirurgie peuvent ne pas être au courant de certaines parties des soins qui leur seront prodigués pendant la chirurgie. La relation entre le sexe du patient et le niveau de confort dans la salle d'opération neurochirurgicale n'a jamais été étudié antérieurement. Notre objectif était de mieux comprendre, au moyen d'une évaluation qualitative des besoins, la perception qu'ont les patients de l'environnement dans la salle d'opération, entre autres en ce qui touche le personnel, les observateurs, le rôle des étudiants en médecine, le cathétérisme, le degré de nudité et le verbiage. Méthodes : Vingt patients (14 femmes et 6 hommes), qui avaient subi une intervention neurochirurgicale sous AG au cours des deux dernières années, ont participé à des entrevues face à face semistructurées. La majorité avaient subi une craniotomie pour des tumeurs bénignes. Les entrevues ont été transcrites et soumises à une analyse thématique modifiée. Résultats : Neuf thèmes sont ressortis des entrevues : 1) la perception de l'environnement opératoire varie selon le sexe ; 2) le manque de connaissances concernant les observateurs est anxiogène pour les femmes ; 3) ne pas connaître l'implication directe des étudiants est préoccupante pour tous les patients ; 4) il est important de prévenir les patients de l'implantation de matériaux étrangers et permanents ; 5) le cathétérisme provoque de l'anxiété chez les femmes ; 6) une vérification de la présence de menstruations avant la chirurgie peut minimiser la gêne chez les femmes ; 7) les patients perçoivent les conversations superflues comme une distraction pour les chirurgiens ; 8) les patients font confiance à leur chirurgien ; 9) il existe une relation entre le sexe de la personne qui effectue l'entrevue et le confort du patient pendant l'entrevue. Conclusion : Bien que la plupart des patients, hommes ou femmes, ne soient pas conscients des activités dans la salle d'opération, ils ne sont généralement pas craintifs parce qu'ils font confiance à leur chirurgien. Les femmes semblent avoir besoin de plus d'information. Les besoins des patients en termes d'information doivent être satisfaits sans provoquer d'anxiété, tout en préservant leur sens de modestie dans l'environnement intra-opératoire.

Can. J. Neurol. Sci. 2011; 38: 65-71

Pre-operative psychological and emotional preparation in surgical patients is important to help allay anxiety. Patients' preoperative anxiety can be categorized into 'Fears of the Unknown' and 'Fears of Illness' '. 'Fears of the Unknown' include patient dependence on others during anesthesia and surgery, and lack of knowledge about surgical outcomes ${ }^{1}$. 'Fears of Illness' include fears about post-operative complications and the outcome from the disease ${ }^{1}$. Younger female patients, those with lower education, and those with previous negative experiences are more anxious pre-operatively ${ }^{1}$.

Pre-surgical anxiety is a 'Fear of the Unknown.' Studies examining the operating room (OR) environment have focused largely on patients who underwent sedation rather than general anesthetic (GA), and on the role of nurses ${ }^{2}$. Wearing gowns without undergarments under is an example of a peri-operative activity causing embarrassment and anxiety ${ }^{3}$. Staff-patient

From the Department of Surgery, Division of Neurosurgery, University Health Network, University of Toronto, Toronto, Ontario, Canada.

Received June 24, 2010. Final Revisions Submitted August 5, 2010 Correspondence to: M. Bernstein, University Health Network, Toronto Western Hospital, Division of Neurosurgery - 4W451, 399 Bathurst Street, Toronto, Ontario, M5T 2S8, Canada. 
relationships and providing patients with information are major factors in patient satisfaction with peri-operative care ${ }^{2}$.

Adult female surgical patients have been found to be more fearful than men $^{4}$. Female patients undergoing outpatient surgery have been found to be more eager for information than men $^{3,5}$.

We performed a qualitative study to explore some specific sources of potential discomfort for neurosurgical patients including gender-specific issues.

\section{MeTHODS}

\section{Study Design}

Qualitative case study methodology was employed, using semi-structured face-to-face interviews.

\section{Setting and Participants}

Study participants included patients of the senior author attending routine follow-up assessment in the ambulatory clinic at the University Health Network, a quaternary care metropolitan teaching hospital. Inclusion criteria included: 1) patients who underwent any neurosurgical operation under GA within the last two years; 2) age 18 years and over; 3 ) ability to speak and understand English; and 4) intact cognition.

\section{Sample Size}

Twenty to thirty interviews were sought to achieve saturation, which refers to the point where no additional themes are likely to surface ${ }^{6}$.

\section{Data Collection}

Face-to-face interviews were based on a semi-structured guide (Table I), which was reviewed for face and content validity. The guide was developed to explore patient understanding of the OR environment in five main areas: i) observers; ii) medical students; iii) implantation of foreign materials; iv) gender sensitivity issues; and v) intra-operative conversations. Interviews were audio-recorded and transcribed. Demographic data were collected for all participants.

\section{Data analysis}

Modified thematic analysis was undertaken by two reviewers. Using open and axial coding overarching themes were developed ${ }^{7}$.

\section{Research Ethics}

The study was approved by the hospital's Research Ethics Board. Informed consent was obtained from each participant. All transcripts and demographic data were anonymized.

\section{RESULTS}

\section{Patient Information}

Twenty patients were interviewed between January 2009 and May 2009 (six males and 14 females). Demographic information was collected (Table 2). Analysis of the interviews generated nine themes, which are discussed below and illustrated with verbatim quotes.

\section{Perception of the intra-operative environment varies between} male and female patients

The majority of female patients noted the busy nature of the operating room, the presence of numerous unidentified individuals, and the surgical equipment, and half of the women found these factors daunting. "The last person you see is somebody you don't know, and it's kind of a weird feeling." "When I was first wheeled in, I was petrified. It reminded me of NASA, with all the heavy machinery and the equipment."

Men's perception of the intra-operative environment focused on the highly efficient nature of the OR team. No man expressed concern regarding the number of individuals in the room, or discomfort relating to the OR environment. "The environment was professional. It's almost choreographed so there is no wasted time. There were a lot of people in there when I was there and they made me feel really comfortable."

\section{Lacking awareness about observers is anxiety-provoking for female patients}

Almost all female patients were unaware of the possibility of observers being present in the OR. Female patients were disapproving of observers who were hospital administrators or surgical company representatives, but were more comfortable with medical students or foreign trained surgeons. Male patients were comfortable with observers in the OR, and were equally accepting of medical trainees and non-medical people. While most patients thought that meeting observers was not necessary, they desired to be informed about observers.

Most females were opposed to the presence of observers while they were partially or fully naked, regardless of the gender of the individual. "I think it's a private thing between me and my doctor, and I don't want to be on display for anybody." Both female and male patients believed that observers should not be present during patient exposure and positioning unless it was directly relevant.

\section{Being unaware of the hands-on involvement of students is a concern for all patients}

Most patients were surprised at a medical student's potential involvement in superficial aspects of a neurosurgical operation, such as suturing during closing or placing a burr hole in the skull. Even though patients were concerned most by students' inexperience, the majority appreciated their need to learn. "It's like the first time you go and cut your hair... Would you like a student? But they have to do it because that's how they're going to learn right? But I would be a bit afraid."

More invasive procedures heighten patient anxiety and decrease patient acceptance of students. "An incision or sewing something up is... a relatively safe thing, there shouldn't be anything that goes wrong....Drilling the hole in the skull, my comfort level decreases." While most patients wished to be informed pre-operatively regarding a student's role, the desire to meet them was inconsistent. Ultimately, adequate supervision of students by the staff surgeon is the most important factor in relieving the patient's anxiety.

Male patients did not believe patients had the right to refuse students being involved in their care, whereas female patients were divided on this issue. Some believed that patients have the 


\section{Table 1: Interview guide}

Thank you for agreeing to participate in this interview. You have been selected because you have undergone a neurosurgical operation while asleep. The purpose of this interview is to find out your perception of the operating environment. Learning more about patients' understanding, concerns and needs after having undergone surgery while asleep, allows surgeons to gain insight into these matters, and may enable them to address these issues with future patients in advance, to ensure patient dignity and respect is maintained during surgery, for both men and women. A series of questions and hypothetical scenarios regarding five different aspects of the intra-operative environment will be presented to you. There are no right or wrong answers. The questions may not relate specifically to your care or clinical situation, and are standardized for all participants. Your privacy will be maintained at all times.

\section{General Questions}

1. What is your perception of the environment in the operating room? Did you have any fears or concerns about the environment itself, unrelated to the surgery? Please tell me about your previous surgeries.

\section{i) OR Staffing / Observers}

2. What is your understanding of who may have been involved in your care in the operating room? If you had the opportunity, would you have liked to meet any of these individuals?

a. If yes: Who would you have liked to meet and why?

b. If no: Why not?

3. Before your surgery in the operating room, if you had had the opportunity to give any specific recommendations to how you would like to have been treated, would you have wanted to?

a. If yes: What would they be and why?

b. If no: Why not?

4. Often, observers, who are not members of the patient's health care team, are present during surgery in the operating room. They have hospital permission to observe the operation. Observers may include medical students, hospital administrators, foreign-trained surgeons or corporate representatives.

a. What are your thoughts about observers being present during a patient's operation?

b. If a 1st and 2nd year medical student or foreign-trained surgeon were to have observed during your operation, would you have desired to be informed and/or meet the individual?

c. If a hospital administrator or corporate representative were to have observed during your operation, would you have desired to be informed and/or meet the individual?

d. Should you have the right to refuse the presence of observers during your operation? Why?

ii) The Role of Medical Students in the OR

5. Clinical clerks, who are 3rd and 4th year medical students, may be involved in a patient's surgery, for example in cutting the scalp, the placement of holes into the skull, sewing up the incision at the end of the operation.

a. Are you aware of the involvement of clinical clerks in the operation itself? What are your thoughts about this?

b. Would you be concerned if a clinical clerk were involved in your operation and would you want further information about their role in advance?

i. What factors would make your more or less concerned about their involvement in your care?

c. Should patients have the opportunity to meet or the right to refuse the involvement of clinical clerks in their care or

in their operation?

iii) The Implantation of Foreign Materials

6. Foreign synthetic and non-human materials may be implanted into patients during surgery.

a. At the end of every brain surgery, titanium screws are used to re-insert the patient's piece of skull bone. They have no medical consequence to the patient in that there are no long-term adverse medical complications associated with their insertion.

i. Should patients be told in advance about the implantation of these screws? Please explain.

b. In certain brain operations, the dura, which is the outermost layer of tissue covering the brain, needs to be partially replaced

with what is known as a "dural graft," which may be from a non-human animal source such as a pig or cow, or may be synthetic. i. Should patients be informed in advance about the possible need of a dural graft? Should patients be given a choice regarding the selection of the material of the graft?

1. Do cultural or religious factors play a role in your answer?

c. In some back operations a metal device is used to produce a fusion so the bones do not move on each other.

i. Should patients be informed in advance about this metal device? Please explain.

iv) Gender Sensitivity Issues

7. After a patient is asleep, usually a tube is inserted into their bladder via their urethra, which collects their urine in a bag during their operation. This is referred to as catheterization. 
Table 1: Interview guide (part 2)

a. Are you aware that this occurs? Do you believe patients should be explicitly told about this in advance? Do you have any concerns about catheterization?

b. Should patient gender match the gender of the health care professional performing the catheterization? Should patients have the option to request the gender of the individual catheterizing them? Please explain.

i. Does your common sense of modesty, cultural background or religious beliefs influence your answer?

8. After a patient is asleep, the patient's gown may be removed and he/she may be partially or fully nude while they are placed into the appropriate position and are prepped for surgery. In back surgery, the patient may be positioned "on all fours" in order to access the spine.

a. Should patients be informed about this prior to surgery?

b. Is your modesty an issue to you in the operating room?

c. Should observers be present in the operating room during this time? Would the observer's gender or position influence your decision?

9. For female participants

a. Should all surgeons ask their female patients at the time of surgery whether or not they currently have their period?

i. Would you be comfortable with your surgeon asking you whether you had your period at the time of surgery?

Does surgeon gender influence your answer?

ii. If your surgeon were male, would you prefer to be asked by a female member of your health-care team (nurse, medical student, resident)?

b. If you had your period at the time of surgery, would you voluntarily tell your surgeon?

i. Does surgeon gender influence your answer?

c. Does your common sense of modesty, cultural background or religious beliefs influence your above answers?

\section{v) Verbiage}

The remaining questions will focus on hypothetical scenarios that I will run through. They in no way relate to your specific operation, surgeon or health-care team. We are interested in knowing what you think about each one.

10. Some surgeons play music during the operation. What are your thoughts?

11. While operating on an asleep patient, the surgeon was discussing topics unrelated to their case, such as social events, a staff party, and telling jokes.

a. What are your thoughts about this?

12. While operating on an asleep patient, the surgeon was discussing another patient's case.

a. What are your thoughts about this?

13. Did this interview make you anxious? Is there anything you would like to add?

14. Did my gender as a female alter your responses? Did your neurosurgeon's gender as a male alter your responses?

right to refuse medical students in their care, whereas others believed that by seeking treatment at a teaching hospital, patients' acceptance is implicit. "You go to a teaching hospital, you get the benefit of people who stay up to date, and so then you have a responsibility to accept their conditions and their training other people who have a right to be there learning."

\section{Disclosure of implantation of foreign and permanent materials into patients is important}

Many participants expressed surprise about the metal implants that were used to re-attach the bone flap. Some patients viewed a surgeon's failure to disclose the implantation of foreign materials pre-operatively as suspicious. "If you don't tell them then it's almost like you're hiding something." Patients wished to be informed about this pre-operatively by their surgeon. Patients' concerns related to the permanence of the implanted material, and the possibility of complications like screw loosening, activating metal detectors at airports, and ability to undergo magnetic resonance imaging.

Patients requiring a dural graft were not necessarily informed pre-operatively by their surgeon. Almost all male and female patients wished to be advised about this possibility. Informing participants about an animal-derived dural graft evoked disgust in some women. However, most patients wanted to receive the best material, regardless of its origin, relying on their surgeon's expertise. Most patients articulated the need for surgeons to discuss the material selection with patients, and offer them a choice, as it may be relevant to patients from certain cultural or religious backgrounds. "I guess for religious reasons some people would say I don't want any part of a pig inside me and 
refuse it...I could see how a religious Jew or a maybe a Muslim would find that important."

\section{Catheterization is anxiety provoking for female patients}

In general, men were not concerned by nudity or positioning during surgical preparation. Many female patients were unaware about catheterization unless they had previously experienced the procedure. There was no consensus among females regarding informing patients about catheterization pre-operatively. Half of the women believed patients should be informed pre-operatively about catheterization. Half the women and most men believed that if catheterization was required for the operation, patients need not be informed.

Both men and women's foremost priority regarding catheterization was the health care practitioner's experience and ability, and gender-concordance in catheterization was of little importance to male patients. One male patient with a medical background differentiated the importance of considering genderconcordance for catheterization between men and women: "I think for ladies it's important. They would prefer a lady doing it rather than a gent doing it. I think men are less particular about...not the privacy but the modesty of the whole thing". If given the option, many female patients would prefer to have a woman performing catheterization. "I'm a little old lady and I don't think I'd like a man to, you know, fiddle around there." "People decide themselves if they want to have a gynecologist who's a man or if they want to have one who's a woman. So... it seems like a very easy thing to have that choice."

\section{Pre-operative menstruation screening may minimize embarrassment for women}

Many female patients would not voluntarily disclose preoperative menstruation to their surgeon. They articulated that it was the surgeon's responsibility to screen female patients for active menstruation if it were medically relevant. Even though menstruation is a private and embarrassing topic for many women, they would be comfortable discussing it with their male surgeon. Women with a history of menorrhagia emphasized the importance of discussing menstruation pre-operatively. "I'm a heavy bleeder and if I get my period, can you tell me what's going to be done about that...it's just a question of embarrassment."

\section{Patients perceive extraneous conversation as a source of distraction for surgeons}

Ambient music in the intra-operative environment was universally not a source of concern for patients; patients believed it might relax surgeons and improve their concentration. In contrast, patients perceived surgeons actively engaging in discussion as inappropriate, and that the content was significant in determining the conversation's acceptability. Dialogue pertaining to other surgical patients' cases was far more disturbing to patients than social chatter. Patients perceived this to increase the surgeon's likelihood of performing a technical error, and viewed it as an infringement on patient confidentiality. "One is the question of keeping in focus. Number two is the privacy of the other patient."
Table 2: Gender stratified summary of characteristics in the 20 patients interviewed

\begin{tabular}{|c|c|c|}
\hline Characteristic & Female $(n=14)$ & Male $(\mathrm{n}=6)$ \\
\hline \multicolumn{3}{|l|}{ Age (years) } \\
\hline Range & $21-74$ & $45-77$ \\
\hline Mean & 50 & 59 \\
\hline Median & 55 & 58 \\
\hline \multicolumn{3}{|l|}{ Neurosurgical operation } \\
\hline Craniotomy & 10 & 4 \\
\hline Discectomy (lumbar) & 3 & 2 \\
\hline Spinal tumor resection & 2 & - \\
\hline \multicolumn{3}{|l|}{ Time since operation (days) } \\
\hline Range & $13-364$ & $16-177$ \\
\hline Mean & 100 & 70 \\
\hline Median & 49 & 60 \\
\hline \multicolumn{3}{|l|}{ Marital Status } \\
\hline Married & 7 & 3 \\
\hline Single & 3 & 3 \\
\hline Divorced & 1 & - \\
\hline Separated & 1 & - \\
\hline Widowed & 2 & - \\
\hline \multicolumn{3}{|l|}{ Education } \\
\hline Middle School & 1 & - \\
\hline Secondary & 4 & 1 \\
\hline College & 6 & 2 \\
\hline University & 2 & 2 \\
\hline Post-graduate & 1 & 1 \\
\hline \multicolumn{3}{|l|}{ Religion } \\
\hline Protestant & 6 & 2 \\
\hline Roman Catholic & 3 & 3 \\
\hline Jewish & 1 & - \\
\hline Muslim & 1 & - \\
\hline Atheist/Agnostic/No Religion & 3 & 1 \\
\hline \multicolumn{3}{|l|}{ Ethnicity } \\
\hline Canadian & 8 & 5 \\
\hline British & 1 & - \\
\hline Filipino & 1 & 1 \\
\hline Indian & - & - \\
\hline Iranian & 1 & - \\
\hline Italian & 2 & - \\
\hline Jamaican & 1 & \\
\hline \multicolumn{3}{|l|}{ Employment } \\
\hline Employed & 6 & 3 \\
\hline Unemployed & 3 & 2 \\
\hline Retired & 5 & 1 \\
\hline \multicolumn{3}{|l|}{ Past Surgical History } \\
\hline Range & $0-8$ & $0-2$ \\
\hline Mean & 2.5 & 1.7 \\
\hline Median & 2 & 2 \\
\hline No past surgical $\mathrm{Hx}$ & $21 \%$ & $17 \%$ \\
\hline Total \# of operations & 34 & 10 \\
\hline \% Past Sx Hx Neurosurgery & $9 \%$ & $0 \%$ \\
\hline
\end{tabular}

N.B. Patients past surgical history does not include the current neurosurgical operation.

\section{Patients trust their surgeon}

Notwithstanding fears and concerns expressed by both male and female patients, confidence in the surgeon was most important in alleviating anxiety about the issues described above. They extended that same trust to the other healthcare professionals involved in their care: "If I trust the surgeon, I would trust the people who are with him. If I didn't, then I would probably be apprehensive." 


\section{There is a relationship between interviewer gender and patient comfort in the interview}

Men and women did not report anxiety as a result of the questions posed during the interview. Male patients stated their answers were not affected by having a female interviewer. One third of female patients reported they were more at ease with answering personal questions relating to menstruation and exposure with a female interviewer. "The personal ones about, oh a lot of those things, I wouldn't have answered because I wouldn't feel comfortable with a male."

\section{Discussion}

A qualitative needs assessment was used to evaluate male and female patients' knowledge and perception of the OR environment. The relevant literature has been focused outside of neurosurgery in the domain of intra-operative nursing care ${ }^{4,5}$, and anesthesia ${ }^{5}$, and with patients who underwent local or regional anesthesia with sedation ${ }^{7}$. Furthermore, most previous studies involved mailed questionnaires or surveys. The most closely related studies in the neurosurgical literature examined patients' feelings about residents in their care ${ }^{8}$, and patients' experiences undergoing awake craniotomy ${ }^{7,9}$. Our study is the first to address gender-specific attitudes of patients toward the neurosurgical OR environment.

The study's main finding was that although most male and female patients have little knowledge of the activities that occur in the OR, they are generally not fearful as they place full trust in their surgeon's judgment and expertise. Surgeons' recognition of patients' trust has been demonstrated previously ${ }^{10}$. Even though all patients consented to treatment as per University Health Network (UHN's) consent form, the majority of both male and female patients reported they were unaware of the presence of observers in the OR and the involvement of students in their care. Apparently patients are not reading the consent form prior to signing it, or their recall of the consent process is poor.

Neurosurgical patients' lack of knowledge about residents was demonstrated previously ${ }^{8}$. Most patients believed it is the surgeon's responsibility to inform them pre-operatively about observers and the hands-on involvement of students in the OR. It has been demonstrated previously that surgeons do not voluntarily tell patients about the role of residents in their care ${ }^{10}$, so it is expected that they do not voluntarily inform patients about the role of medical students or observers. In contrast to residents, the hands-on role of medical students is generally highly supervised and much more limited in scope and shorter rotations

Female patients' greater desire for peri-operative information regarding anesthesia including bladder catheters has been previously established in a cross-sectional study ${ }^{5}$. In our study, women's greater desire for information was unrelated to ethnicity, marital status or religious background. Our findings suggest that female patients' greater information needs may be associated with their concern for their personal sense of modesty over their body. Gender concordance for those performing procedures with the potential to compromise females' modesty, such as catheterization, may lessen patients' vulnerability and increase their comfort.
This needs assessment was a qualitative case study not intended to be generalized to all neurosurgical patients. This study may serve to enhance neurosurgeons' general appreciation for gender differences in relation to patients' OR needs and may impact their approach to pre-operative discussions with all surgical patients.

For most even though it may be initially anxiety provoking to consider certain aspects of the OR environment, this is preferred to post-operative discovery and it removes the possibility of patients questioning trust in their surgeon. By communicating with patients pre-operatively about their fears of the unknown in the OR, patients have the opportunity to be empowered to regain a sense of control. Cardiovascular surgery patients empowered to become more involved in their treatment had increased patient satisfaction and superior recovery ${ }^{11}$.

\section{Limitations of the Study}

By using a semi-structured interview guide, over- or underinvestigation of certain topics may have resulted. It is also conceivable that patients may not have articulated their feelings candidly. To minimize this possibility, patients were reassured their neurosurgeon was not informed whether or not they participated and that their interview was anonymized.

All participants had a positive outcome in that they did not experience a serious surgical complication, so their responses may have been biased in a positive direction.

An element of recall bias must be considered with retrospective assessment; however, most patients were interviewed within three months following their operation. Despite the potential for recall bias, the strength of the retrospective approach was two-fold. Firstly, all patients had visited the pre-admission clinic, and had received standardized information pre-operatively. Secondly, this approach avoided heightening anxiety for patients before surgery.

The relative absence of males' specific needs in the OR and an overall decreased desire for information may be an accurate portrayal or may be attributable to the small sample size. One third of women felt more comfortable answering questions with a female interviewer. It is possible that male patients felt less comfortable with a female interviewer although this was not expressed. Under ideal circumstances and with more resources and time, both a male and a female neurosurgeon's practices could be evaluated, whereby patients from either practice could be randomized to a male or a female interviewer. Patients' views concerning the intra-operative environment may vary by patient population, surgeons' practices, and institutions' policies regarding disclosure, or with different healthcare systems.

\section{Conclusions}

\section{Recommendations}

I) Surgeons should inform patients about the nature of potential non-medical observers and the reason for their presence. Observers should enter the room once the patient is under GA, unless the preparation is central to their observation.

II) Neurosurgeons should educate patients on the role of medical students in the OR pre-operatively, emphasizing that it is an important part of their 
training, and reassuring patients they have adequate supervision.

III) Neurosurgeons should inform patients about the implantation of foreign and permanent materials and reassure patients of their medical safety. The role of culture and religion should be considered in patients who require a dural graft or any material derived from an animal. Surgeons should engage patients in the selection process of the material up-front.

IV) Whenever possible, gender concordance between the healthcare provider performing catheterization and the patient should exist.

V) Female patients should be screened regarding active menstruation pre-operatively, to reassure them that their personal hygiene and dignity are maintained.

VI) Beyond patient safety, the OR team's utmost priority should be maintaining patients' privacy in relation to their medical health and their body.

\section{ACKNOWLEDGEMENTS}

The authors thank Dr. Kathleen Khu and Ms. Diane Cartwright for their help. Initially, this study was developed as a self-initiated project for the Determinants of Community Health II course at the University of Toronto, Faculty of Medicine.

\section{REFERENCES}

1. Kindler C, Harms C, Amsler F, et al. The visual analogue scale allows effective measurement of preoperative anxiety and detection of patients' anaesthetic concerns. Anaesth Analg. 2000;90(3):706-12.

2. Caljouw MA, van Beuzekom M, Boer F. Patient's satisfaction with perioperative care: development, validation and application of a questionnaire. B J Anaesth. 2008;100(5):637-44.

3. Kain ZN, Kosarussavadi B, Hernandez-Conte A, Hofstader MB, Mayes LC. Desire for perioperative information in adult patients: a cross-sectional study. J Clin Anesth. 1997;9(6): 467-72.

4. Graham LE, Conley EM. Evaluation of anxiety and fear in adult surgical patient. Nurs Res. 1971;20(2):113-22.

5. Koivula M, Paunonen-Ilmonen M, Tarkka MT, Laippala P. Gender differences and fears in patients awaiting coronary artery bypass grafting. J Clin Nurs. 2001;10(4):538-49.

6. Strauss A, Corbin J. Basics of qualitative research: grounded theory procedures and techniques. Beverly Hills: Sage Publications Inc; 1990.

7. Palese A, Skrap M, Fachin M, Visioli S, Zannini L. The experience of patients undergoing awake craniotomy: in the patients' own words. A qualitative study. Cancer Nurs. 2008;31(2):166-72.

8. Knifed E, July J, Bernstein M. Neurosurgery patients' feelings about the role of residents in their care: a qualitative case study. J Neurosurg. 2008;108(2):287-91.

9. Khu KJ, Doglietto F, Radovanovic I, et al. Patients' perceptions of awake and outpatient craniotomy for brain tumor: a qualitative study. J Neurosurg. 2010;112(5):1056-60.

10. Knifed E, Taylor B, Bernstein M. What surgeons tell their patients about the intraoperative role of residents: a qualitative study. Am J Surg. 2008;196(5):788-94.

11. Trummer UF, Mueller UO, Nowark P, Stidl T, Pelikan JM. Does physician-patient communication that aims at empowering patients improve clinical outcomes? A case study. Patient Educ Couns. 2006;61(2):299-306. 